\title{
Topology Optimization and Design Guidelines of Sub- Stiffened Panels in Aerospace Applications
}

\author{
Hemza Layachi ${ }^{\mathrm{a}}$, Yuan-ming Xu and Mohamed Amine Bennaceur \\ School of Aeronautic Science and Engineering, Beihang University, Beijing 100191, China
}

\begin{abstract}
The present work is a proposed optimization model of grid sub-stiffened panels for aerospace applications, having a better knowledge about the stability analysis of conventional grid sub-stiffened panels against loading and different mode of failure occurring lead us thinking about the topology optimization. In a first stage, we will analyse the stability performance of such structures against specific mechanical loading and conclude some techniques to introduce a topology optimization through PSO algorithm of some design variables. The aim is the better exploitation of the sub-stiffened panel along the plan so that the area less stressed due the charging will be extruded in mass for the enhancement of the concept of looking for better performance with a structure already saved in weight.
\end{abstract}

\section{Introduction}

Stiffened panels are primary structures in aerospace engineering as for nuclear, power plate, marine and civil buildings. Stiffening structures is a techno-economic compromise that offer weight saving by using less manufactured material against subjected load conditions, it is more practical to use additional stiffeners than just increasing of thickness of the plate [1,2]. The common way to optimize stiffened panel's performances in aerospace application has to start with calculating the critical loading, more the structure is needed to carry loads more it has to be better reinforced [3, 4]. It is significant to give a structural design that handle the listed issues. One of the alternative solutions is to introduce a topology optimization to such structures along the plan, as the terminology suggests basing on the study of geometric properties and response of the stiffened panels to mechanical charging by changing the sizes and shapes of figures in question $[5,6]$.

Topology optimization in design of aircraft structures have been applied in successful industrial case studies [7, 8]. This brand of research develop mathematical and numerical models to optimize material location in design varieties [9], defining the input variables of the proposed design, the basic optimization methodology starts with defining a range of maximum $/ \mathrm{minimum}$ of parametric variables [6]. Grid-stiffened structure with equilateral rectangular patterns give noticeable strength performance for lightweight against mechanical charging and damage [10]. The repetitive pattern represented by the stiffeners along the panel is also an important factor in minimizing manufacturing cost and complexity of design in one part and, a possibility of such a topology optimization in second part.

\footnotetext{
${ }^{a}$ Corresponding author : layachi-hamza@hotmail.com
} 


\section{Topology optimization procedure}

In a first stage, we will focus on the response of a conventional grid sub-stiffened panel to compression load, the first buckling modes will be inspected and the critical load to buckling will be defined. We will look, in such conditions, to the distribution of charging due to the loading. Some zones will be more or less affected so the lesser-charged areas will be enhanced for a topology optimization.

In the table 1we list, the different buckling modes may occur due to charging to the structural panel.

Table 1. Buckling modes and its modality through the stiffened panel.

\begin{tabular}{|c|c|c|}
\hline $\begin{array}{c}\text { Buckling } \\
\text { mode }\end{array}$ & Modality \\
\hline $\begin{array}{c}\text { Local } \\
\text { buckling }\end{array}$ & $\begin{array}{c}\text { This is happening when the junction between plate } \\
\text { and the stiffener does not displace in a vertical way } \\
\text { and buckling is located on the skin of the panel. }\end{array}$ \\
\hline $\begin{array}{c}\text { Torsional } \\
\text { Buckling }\end{array}$ & $\begin{array}{c}\text { With a local buckling mode, this junction is still stiff } \\
\text { and straight. }\end{array}$ \\
\hline $\begin{array}{c}\text { Partial } \\
\text { buckling }\end{array}$ & $\begin{array}{c}\text { Stiffeners buckle in torsional mode, partial buckling } \\
\text { of a panel is when sub-stiffeners are unbuckled. }\end{array}$ \\
\hline $\begin{array}{c}\text { Overall } \\
\text { buckling }\end{array}$ & $\begin{array}{c}\text { Catastrophic buckling mode, we observe the buckling } \\
\text { of the whole panel as a column including the skin, } \\
\text { stiffeners and sub-stiffeners. }\end{array}$ & \\
\hline
\end{tabular}

We modify the disposition of the stiffeners and sub-stiffeners along the panel in such a way we extrude in weight, for this we will go through those design guidelines basing on simplifying hypothesis.

Figure 1 give the plan of the targeted topology optimization, we start by the performance of a conventional grid panel in such a way it's given in the best configuration, we look for the possibility of introducing topology optimization procedure through the panel. Dimensioning of selected repetitive patterns will be applied on the stiffeners by comparative study taking care of the conception and manufacturing difficulties

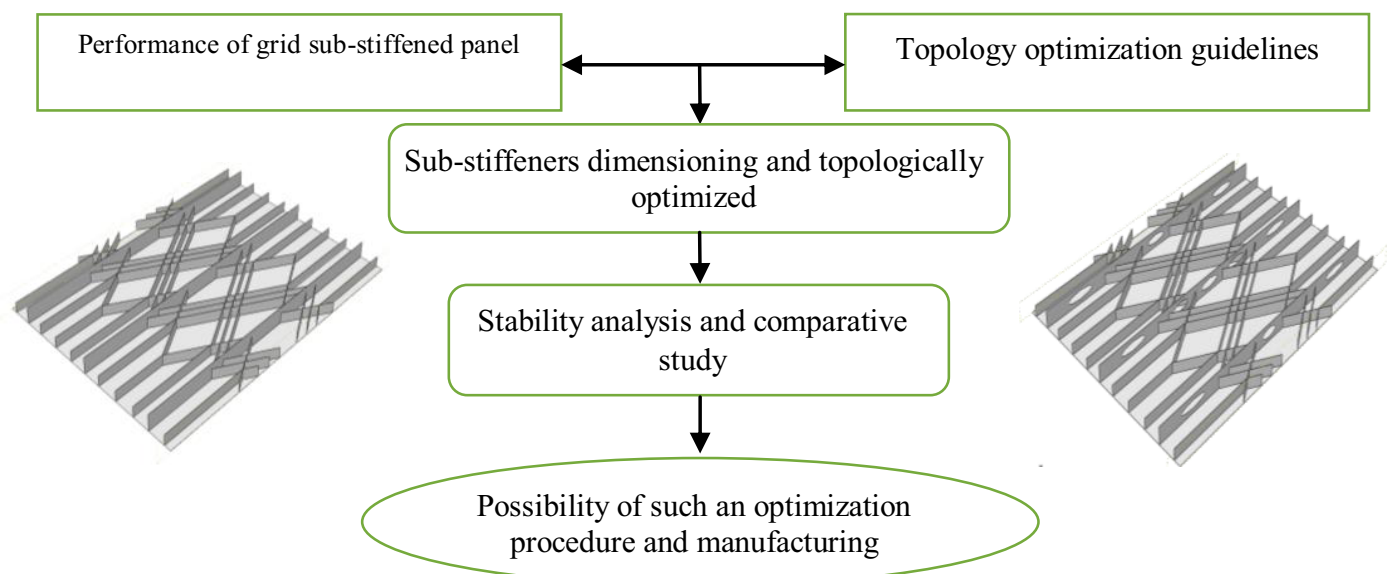

Figure 1. Plan of topology optimization study 
- Topology optimization will be applied on the stiffeners due to its capacity to maintain the stability of the sub-stiffened panels in one part and the ability of extruding some material from it, since the plate is conserved in design and sub-stiffeners are typically small for such a topology.

- We opted to introduce elliptic patterns through the stiffeners for topology optimization since it is validated for better performance against crack and fissure propagation and easy in conception, which is more adequate for this study since the sub-stiffened panel will be subjected to compression load.

- The extruded material is a function of the behaviour on the conventional sub-stiffened panel, basing on its response to the imposed loading, we will work on the dimensioning and positioning of the extruded material in a way we guarantee the stability and better performance comparing to the conventional sub-stiffened panel.

\section{Case study}

In this study and starting from the classic configuration we will investigate the stability performances of sub-stiffened panels, we focus on the buckling and post buckling due to compression load. The critical load and buckling modes will be defined for it in a first stage. The optimization procedure consists to look for the substitute that the structure will be buckled locally which was concluded from previous studies [11] which, give us a possible way to introduce our topology procedure through its stiffeners.

The sub-stiffened panel will be subjected to compression load, figure 2 represent the initial grid panel with its specific dimensions, design variables for the given structure will be dimensioning peer a cross section, the best configuration interpolating stiffeners and sub-stiffeners thickness and high for maximum performance

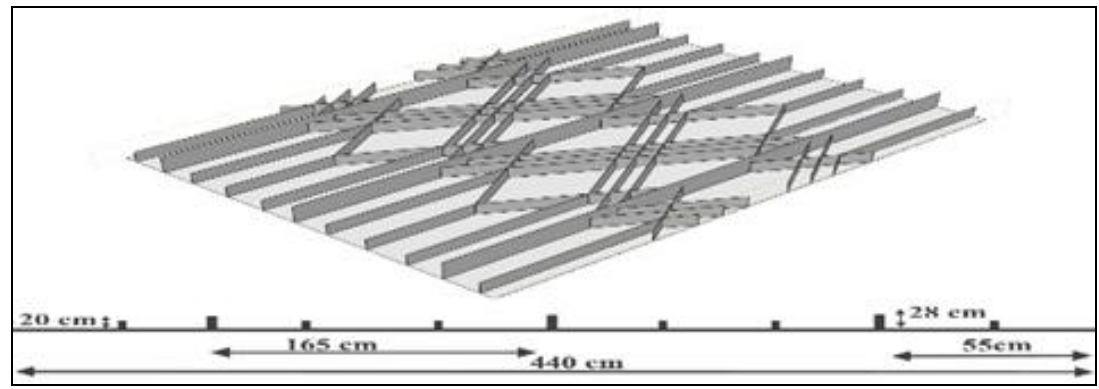

Figure 2. Grid sub-stiffened panel and dimensioning.

Table 2 list the design variable for the grid panel, the respective weight of it, the manufactured material is an Aluminum alloy 2024T3, and here under is the material proprieties of it, as for the topology-optimized panel that will not be changed in material properties and dimensioning.

Table 2. benchmark grid panel design variables and mechanical properties.

\begin{tabular}{|c|c|c|c|}
\hline \multicolumn{2}{|c|}{ Design variables grid sub-stiffened panel } & \multicolumn{2}{l|}{ Mechanical proprieties } \\
\hline \multicolumn{2}{|c|}{ sub-stiffened panel dimensioning } & Aluminum alloy & $2024 \mathrm{~T} 3$ \\
\hline Plate thickness & $1.9 \mathrm{~mm}$ & density & 2770 \\
\hline Stiffeners thickness & $2.8 \mathrm{~mm}$ & Young modulus & $73.1 \mathrm{GPa}$ \\
\hline Sub-stiffeners thickness & $2.8 \mathrm{~mm}$ & Poison ratio & 0.33 \\
\hline Distance per stiffener/sub stiffener & $55 \mathrm{~cm}$ & $\begin{array}{c}\text { Expansion modulus } \\
\mathrm{N} / \mathrm{m}\end{array}$ & 2.3210 \\
\hline Conventional panel mass & $2.118 \mathrm{Kg}$ & Yield stress & $324 \mathrm{MPa}$ \\
\hline
\end{tabular}

Figure 3 give in detail the process of the designed topology optimization for the stiffeners, it involves the extrusion of elliptic patterns $P_{i}\left(L_{i}, W_{i}\right)$ which is modeled in the equations below, in aim to 
get maximum performance comparing to the grid panel an avoid the damage of the stiffeners $\sigma_{\max }$. The repetitive elliptic extrusion through stiffeners is the same along the plan:

$$
\begin{gathered}
P_{i}\left(L_{i}, W_{i}\right) ; \quad\left(X^{2} / L^{2}\right)+\left(Y^{2} / W^{2}\right)=R / 4 \\
\sigma_{\max }<\sigma_{s} \\
D_{\text {in }} \leq D_{\text {in-max }} \\
P_{\text {in }} L, W \leq P_{\text {in-max }} L, W \\
P_{c} L, W \leq P_{c-\text { max }} L, W \\
P_{\text {min }}<P_{i}<x_{\max }, i=1, \ldots, n
\end{gathered}
$$
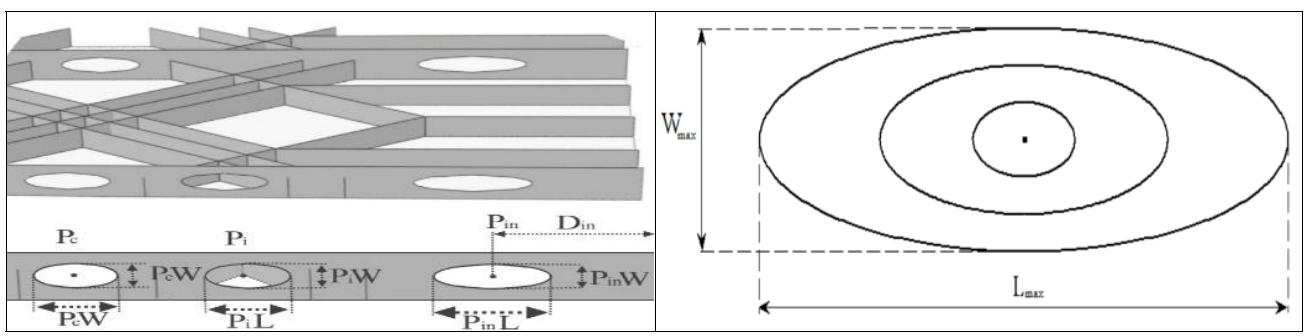

Figure 3. Topology procedure along the stiffeners and dimensioning.

\section{Simulation and results}

\subsection{Buckling analysis}

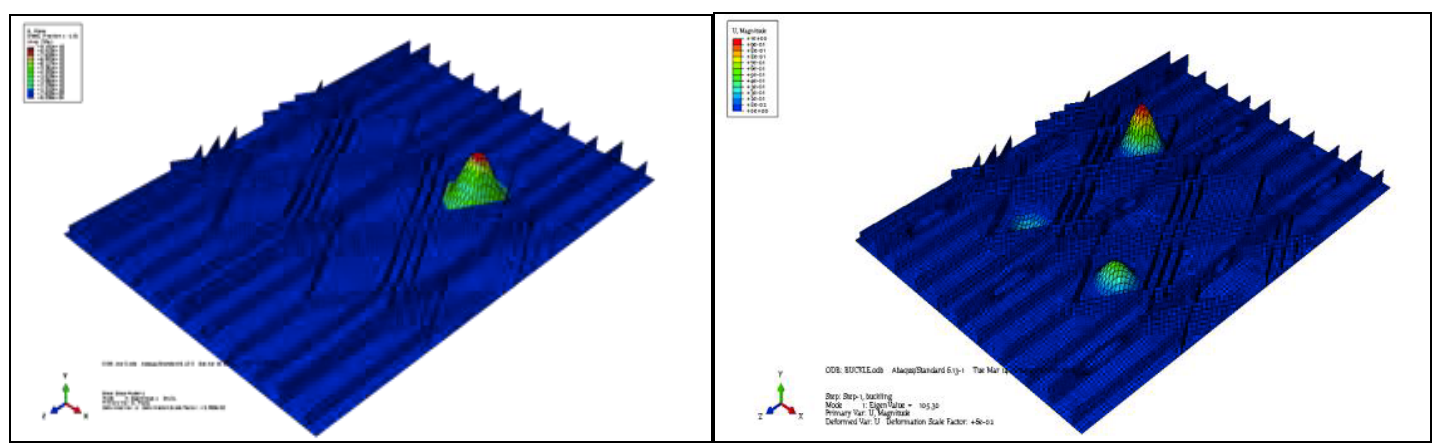

Figure 4. Buckling analysis for structural varieties.

In figure 4, as the results of simulation show, the two proposed sub-stiffened panels buckle in local mode at first stage, which is a great buckling mode due to the capacity of the structure to sustain the loading for more. Even the optimized panel give a greater number of half-wavelet comparing to the conventional one.

Table 3. Buckling analysis results and critical loads.

\begin{tabular}{|c|c|c|}
\hline Structure panel design & $\begin{array}{c}\text { Grid sub-stiffened } \\
\text { pane }\end{array}$ & $\begin{array}{c}\text { Topology optimized grid } \\
\text { panel }\end{array}$ \\
\hline Critical load (Kn ) & 222.4 & 222.2 \\
\hline Equivalent Mises stress (Mpa ) & 295.5 & 312.3 \\
\hline First Buckling mode to occur & local & Local \\
\hline $\begin{array}{c}\text { Half-wavelet appeared in a first } \\
\text { buckling mode }\end{array}$ & 1 & 3 \\
\hline
\end{tabular}


From Table 3, the optimized panel have the capacity to carry more load, the critical load is $222.2 \mathrm{Kn}$ that is great similar the conventional panel given at $222.4 \mathrm{Kn}$, the equivalent Mises stress under buckling is set around 295 against $312 \mathrm{Mpa}$ for the two panels. The second part of this study consist to analyze the post buckling range to define the possibility of such a topology optimization.

\subsection{Post buckling analysis}

The instability process analysis pass by stating the ultimate strength capacity defined by the bearing load $[12,13]$, we run our numerical study through nonlinear RIKS algorithm by ABAQUS 6.13 for the proposed structures. The structural damage is expected at the bearing critical load, the aim of this part is to define the limit before collapse:

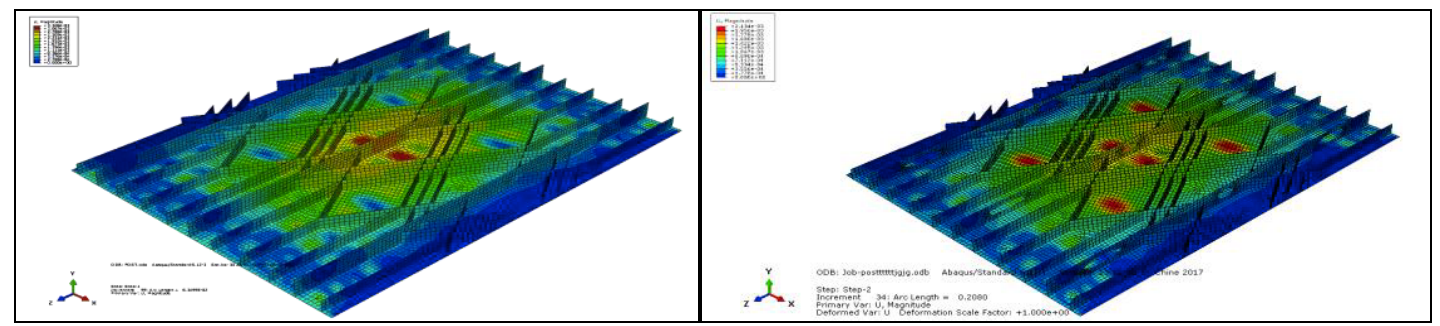

Figure 5. Structural predicted collapse stage.

Figure 5 show the instability process, it is represented by the waveform jumping phenomenon, the buckled surfaces carry more load which affect its stability but it remain local, the two proposed panels have the capacity to sustain the load and keep the structures stable before the bearing load limit.

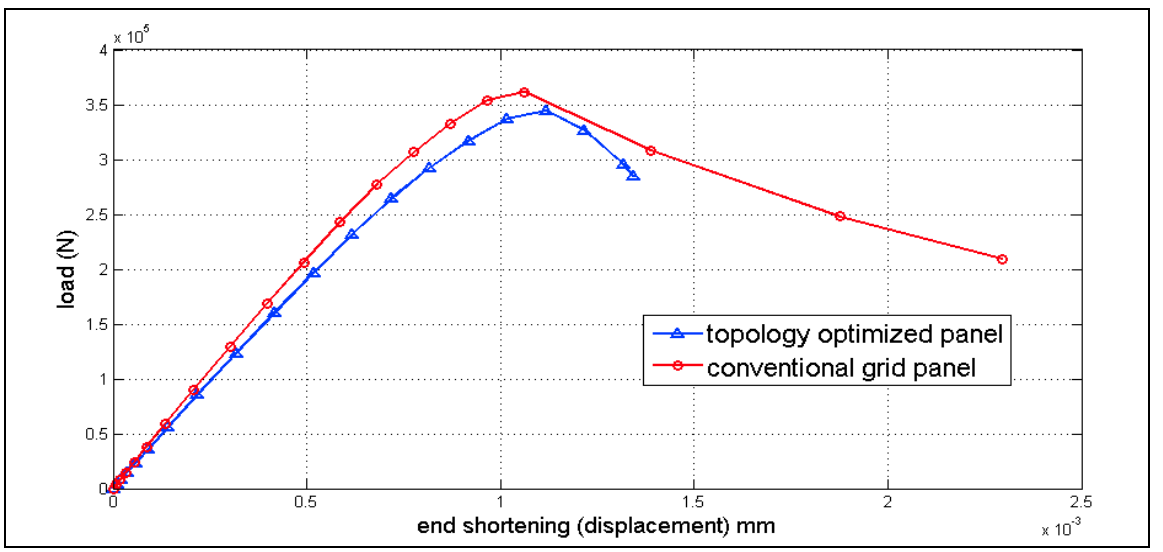

Figure 6. Load Vs end shortening for the structural varieties.

Comparing the results of simulation, we can notice the lesser ratio load/displacement from the second structure to the conventional panel, it is given at $1.4 \mathrm{~mm}$ as a maximum before the collapse against $2.3 \mathrm{~mm}$ for the conventional panel. The ultimate bearing load is slightly lower than the conventional panel given at $345 \mathrm{Kn}$ and $358 \mathrm{Kn}$ respectively for the two panels.

In an overall aspect of analysis and as it is given by figure 5and 6, the stiffeners in both structures remain stable against loading until the failure, it is noticed the multiple stressed zones in the optimized structure than the conventional one but those zones are more located in skin of the sub-stiffened panel. It is more because of the buckling mode in a first stage where the number of half wavelet is greater than conventional panel. 


\section{Conclusion and perspectives}

Topology optimization is a promoting brand of research and engineering in aeronautical science, weight saving for structures remain a necessity looking for better performance and stability. We can conclude from this study the possibility of such a methodology for sub-stiffened panels where topology procedure let us gain 1.5 to $2 \%$ of the total weight of a conventional sub-stiffened panel which saving its stability, this will have great reflection to the performance of the aeronautical structure. Regarding the behavior of the topology optimized sub-stiffened grid panel we highlight its great capacity to maintain the stability of the panel against loading.

\section{References}

1. K. Doshi and S. Vhanmane, Ultimate Strength of Stiffened Plates Subjected to Longitudinal Compression and Lateral Pressure, ASME 33rd International Conference on Ocean, Offshore and Arctic Engineering, V04BT02A051--V04BT02A051 (2014)

2. T. Kubiak, Nonlinear Plate Theory for Postbuckling Behaviour of Thin-Walled Structures Under Static and Dynamic Load. INTECH Open Access Publisher, (2012)

3. Y. XU and S. LI, Approximate calculation method of buckling load on integral sub-stiffened panel, J. Beijing Univ. Aeronaut. Astronaut., 3, 1 (2015)

4. S. B. Mulani, W. C. H. Slemp, and R. K. Kapania, EBF3PanelOpt: an optimization framework for curvilinear blade-stiffened panels, Thin-Walled Struct., 63, 13-26 (2013)

5. B. Stanford, P. Beran, and M. Bhatia, Aeroelastic topology optimization of blade-stiffened panels, J. Aircr., 51, 3, 938-944 (2014)

6. J.-H. Zhu, W.-H. Zhang, and L. Xia, Topology optimization in aircraft and aerospace structures design, Arch. Comput. Methods Eng., 23, 4, 595-622 (2016)

7. S. Grihon et al., Fuselage Structure Optimisation, Adv. Collab. Civ. Aeronaut. Multidiscip. Optim., (2010)

8. M. Tomlin and J. Meyer, Topology optimization of an additive layer manufactured (ALM) aerospace part, Proc. of the 7th Altair CAE technology conference, 1-9 (2011)

9. M. S. Sohn, Topics in structural topology optimization, University of Illinois at UrbanaChampaign, (2010)

10. A. Murphy, D. Quinn, P. Mawhinney, M. Ozakc-a, and S. van der Veen, Tailoring static strength performance of metallic stiffened panels by selective local sub-stiffening, Proc. of the forty seventh AIAA/ASME/ASCE/AHS/ASC structures, structural dynamics, and materials conference. Newport, Rhode Island, 1, 4, (2006)

11. H. Layachi and Y. Xu, Performance and Stability Analysis of Sub-stiffening for Mechanical Buckling and Post Buckling: A Selective Study, MATEC Web of Conferences, 95, 1004 (2017)

12. T. D. Dang and R. K. Kapania, Ritz Approach for Buckling Prediction of Cracked-Stiffened Structures, J. Aircr., 50, 3, 965-974 (2013)

13. D. G. Stamatelos, G. N. Labeas, and K. I. Tserpes, Analytical calculation of local buckling and post-buckling behavior of isotropic and orthotropic stiffened panels, Thin-Walled Struct., 49, 3, 422-430 (2011) 